\title{
Correlation between functional MRI techniques and early disability in ambulatory patients with relapsing-remitting MS
}

\author{
Al-Amir Bassiouny Mohamed ${ }^{1,3^{*}} \mathbb{0}$, Hesham Abdelghani Algahalan² and Mohamed N. Thabit ${ }^{1}$
}

\begin{abstract}
Background: Multiple sclerosis (MS) is a common neurological disorder which can lead to an occasional damage to the central nervous system. Conventional magnetic resonance imaging (CMRI) is an important modality in the diagnosis of MS; however, correlation between cMRI findings and clinical impairment is weak. Non-conventional MRI techniques including apparent diffusion coefficient (ADC) and magnetic resonance spectroscopy (MRS) investigate the metabolic changes over the course of MS and overcome the limits of CMRI.

A total of 80 patients with MS and 20 age and sex-matched healthy control subjects were enrolled in this crosssectional study. Ambulatory patients with relapsing-remitting MS (RRMS) were recruited. Expanded Disability Status Scale (EDSS) was used to assess the disability and the patients were categorized into three groups "no disability", "minimal disability" and "moderate disability". All patients underwent cMRI techniques. ADC was measured in MS plaques and in normal appearing white matter (NAWM) adjacent and around the plaque. All metabolites concentrations were expressed as ratios including $\mathrm{N}$-acetyl-aspartate/creatine (NAA/Cr), choline/N-acetyl-aspartate (Cho/NAA) and choline/creatine (Cho/Cr). ADC and metabolite concentrations were measured in the normal white matter of 20 healthy control subjects.

Results: The study was carried on 80 MS patients [36 males (45\%) and 44 females (55\%)] and 20 healthy control [8 males (40\%) and 12 females (60\%)]. The ADC values and MRS parameters in NAWM of patients with MS were significantly different from those of the control group. The number of the plaques on T2 images and black holes were significantly higher at "Minimal disability" group. Most of the enhanced plaques were at the "Moderate disability" group with $P$ value $<0.001$. The mean of ADC in the group 1,2 and 3 of disability was $1.12 \pm 0.19,1.50 \pm 0.35,1.51 \pm 0.36$, respectively, with $P$ value $<0.001$. In the group 1,2 and 3 of disability, the mean of NAA/Cr ratio at the plaque was $1.34 \pm 0.44,1.59 \pm 0.51$ and $1.11 \pm 0.15$, respectively, with $P$ value equal 0.001 .
\end{abstract}

Conclusion: The non-conventional quantitative MRI techniques are useful tools for detection of early disability in MS patients.

Keywords: Multiple sclerosis, Early disability, Functional MRI

*Correspondence: amirmohamed3636@gmail.com

${ }^{3}$ Sohag University Hospital, El Kawaser, P.O. Box 82524, Sohâg 82524

Egypt

Full list of author information is available at the end of the article

\section{Background}

Multiple sclerosis (MS), the most common autoimmune neurological disorder, affects about 2.5 million people around the world and characterized by multifocal central nervous system (CNS) damage which leads to progressive neurological dysfunction [1-4]. 
Axonal loss can occur in both acute and chronic stages of MS, as shown by pathological and neuroimaging studies $[5,6]$. It may have important functional consequences, leading to the development of irreversible clinical disability which is not clearly related to inflammatory lesions but is instead associated with diffuse neuro-axonal loss caused by various pathological phenomena $[4,7,8]$.

Kuhlmann et al. have demonstrated that acute axonal damage within MS lesions is most noteworthy during the initial stages of the disease and persists to some extend during the following years [9]. Diffusion MRI provides information about water molecular motion in vivo which is normally diminished in highly organized tissue as in white and gray matter with reduction of the apparent diffusion coefficient (ADC) [10]. Diffusion imaging changes can precede enhancement by gadolinium in hyperacute MS lesions [10, 11]. The ADC value is a quantitative imaging able to overcome limitations of cMRI by providing markers more specific to the underlying pathologic changes [12].

Magnetic resonance spectroscopy (MRS) plays a fundamental role in the study of changes and imbalances in different cell metabolites in patients with MS [13]. $\mathrm{N}$-acetylaspartate (NAA) is one of such metabolites and is considered a marker of neural integrity and function $[14,15]$. A decline in the brain NAA/creatine $(\mathrm{Cr})$ ratio, suggests axonal damage, which is reported in very early stages of patients with MS, such as radiologically isolated syndrome (RIS) [16]. Creatine $(\mathrm{Cr})$ is an another cerebral metabolite and represents cellular metabolism and energy systems and reflects changes in cell density and/or gliosis. [15]. Finally, choline (Cho), is a marker of cellular membrane turnover of phospholipids synthesis and degradation and correlates with phospholipid release during active demyelination $[15,17]$. An increase of the Cho/Cr ratio occurs because of increased membrane cell turnover in active MS plaques and a decrease of NAA occurs in inactive plaques as well as in normal appearing white matter (NAWM) $[8,18]$.

The cMRI is an important modality in detection of characteristic MS lesions. However, a correlation between these MRI findings and clinical disability is weak as most of the abnormalities within NAWM which contribute to the development of disability in MS are subtle and cannot be delineated by these techniques [19-21]. In addition, the health risks should be taken into consideration when using Gd-based contrast agents (nephrogenic systemic fibrosis, Gd retention) [22, 23].

Most of the previous studies investigating the relationship between MRI techniques (conventional or nonconventional) and MS disabilities incorporated primary and secondary progressive MS and selected patients with early and late stages of MS in whom a significant disability has been already occurred. The aim of this cross-sectional study is to assess the relationship between non-conventional MRI techniques including ADC and MRS and the degree of disability in the early stage of relapsing-remitting multiple sclerosis (RRMS).

\section{Methods \\ Patients}

A total of 80 patients with MS and 20 healthy control subjects with age and sex matched were enrolled in this cross-sectional study. Patients were recruited from department of Neurology and Psychological Medicine between July 2018 and September 2019. Patients with RRMS according to McDonald criteria 2017 [24] and mild to moderate disability (EDSS is $\leq 4.5$ ) were recruited in this work. Patients with secondary or primary progressive MS were excluded from this study. Patients with neurological disorder other than MS (MS mimics) were also excluded. An acute attack was defined as the presence of new objective neurological signs lasting for at least $24 \mathrm{~h}$ and were compatible with an MS attack [25].

\section{Methods}

All subjects included in the study were subjected to full neurological evaluation. Expanded Disability Status Scale (EDSS) was utilized to assess the physical disability of patients with MS. An overall score can be given on an ordinal scale ranging from 0 (normal neurological examination) to 10 (death due to MS) [26]. Fully ambulatory patients with $($ EDSS $\leq 4.5)$ were only enrolled in this work and divided into three groups based on their level of disability [26]. Group 1 "No disability" has EDSS from 0 to 1.5, group 2 "Minimal disability" has EDSS from 2 to 3 and group 3 "Moderate disability" with EDSS from 3.5 up to 4.5 .

\section{Conventional magnetic resonance imaging (MRI) techniques}

All MRI studies were done using Philips MR machine Achieva 1.5 T-DS (1.5 Tesla), Germany. The contrast media used was either Omniscan or Magnivist [Gadolinium (Diethelene Triamine Penta acidic acid) ("GdDTPA")], it was administrated intravenously in a dose of $0.2 \mathrm{ml} / \mathrm{kg}$ body weight. The following protocol was used in all cases:

1. Non contrast axial, coronal and sagittal T1WIs (TR $400-550 \mathrm{~m} / \mathrm{s}$, TE $15 \mathrm{~m} / \mathrm{s}$ ).

2. Axial T2WI (TR $3500-4800 \mathrm{~m} / \mathrm{s}$, TE, $110 \mathrm{~m} / \mathrm{s}$ ).

3. Axial, sagittal and coronal FLAIR (TR 9000$9400 \mathrm{~m} / \mathrm{s}$, TE $119-150 \mathrm{~m} / \mathrm{s}$, TI $2470-2800 \mathrm{~m} / \mathrm{s}$ ).

4. Post contrast axial, coronal and sagittal T1WI 2-10 min after administration of gadolinium. 
MRI was used to detect lesions both in the brain and spinal cord. A lesion in MS is defined as an area of focal hyperintensity on a T2-weighted (T2, T2-FLAIR or similar) sequence. Typical MS lesions are round to ovoid in shape and range from a few millimeters to more than one or two centimeters in diameter [27]. A positive contrast enhancement MRI (CE-MRI) was considered whenever a hypointense T1W lesion showed increased signal intensity in T1W images taken 10 min after gadolinium injection. Detection of even one positive lesion was regarded as a positive result, both in DWI and CE-MRI.

\section{Diffusion-weighted MR imaging (DWI)}

Follow-up of cMRI techniques were done during the assessment of DWI and MRS.

The imaging sequence for DWI was a multi-section single shot spin Echo Planar Imaging (EPI) sequence (TR/TE/NEX: 4200/140 ms/1), field of view (FOV) $24 \mathrm{~cm}$, matrix $128 \times 265,5 \mathrm{~mm}$ thickness and interslice gap of $1 \mathrm{~mm}$ with diffusion sensitivities of $b$ values $=0,1000 \mathrm{~s} /$ $\mathrm{mm}^{2}$. ADC maps were calculated automatically by the MRI software and included in the sequence. Measurements of $\mathrm{ADC}$ were made in MS plaques and in the NAWM adjacent and around the plaque as well as scattered areas, the data are collected and included from significant region. ADC values were measured in the normal white matter of the control group. A positive DWI result was defined as any lesion compatible with a true plaque in traditional sequences of MRI with increased signal intensity in DWI that showed variable values of ADC mapping according to stage.

\section{Magnetic resonance spectroscopy (MRS)}

Automatic shimming was employed to compensate for the inhomogeneity of the magnetic field. The line width was less than $10 \mathrm{~Hz}$. The signal of water was suppressed using a chemical shift selective imaging sequence (CHESS). An outer-volume suppression pulse sequence was used to avoid signal contamination from outside the voxel of interest (VOI). The point resolve spectroscopy sequence (PRESS) technique was used for VOI selection, the sequence parameters were $\mathrm{TR} / \mathrm{TE}=2000 / 53 \mathrm{~ms}$, FOV $=150 \times 195 \mathrm{~mm}$, slice thickness $=15 \mathrm{~mm}$, in-plane resolution $15 \times 15 \mathrm{~mm}^{2}$, and number of averages $=1024$. The total acquisition time of the spectroscopic sequences was less than $5 \mathrm{~min}$. A standard software package (Spectra view, Philips) was used for postprocessing the MR spectroscopic data. Spectral signals from voxels matching exclusively frontal-parietal-occipital NAWM without any signs of lesion load manifested on T2-weighted MR images were selected. We measured metabolite concentrations within single voxel (SVS) by calculating the area under the curve. All metabolite concentrations were expressed as ratios of signal intensities, including $\mathrm{N}$-acetyl-aspartate/creatine $(\mathrm{NAA} / \mathrm{Cr})$, choline $/ \mathrm{N}$ acetyl-aspartate (Cho/NAA) and choline/creatine (Cho/ $\mathrm{Cr}$ ). Measurements were made in MS plaques and in the NAWM. In addition, these metabolites concentrations were measured in the normal white matter of 10 healthy control group.

The study was approved by the local ethical Committee on Research Involving Human Subjects. All invited persons were informed in detail about the investigation and voluntarily signed the informed consent form.

\section{Statistics}

The statistical analysis was performed using the Statistical Package for the Social Sciences for window (SPSS 20.0, IBM Corp., Armonk, NY, USA). Qualitative data were represented as frequencies and relative percentages. Quantitative data were expressed as mean \pm SD (Standard deviation). Data were analyzed using the student $t$ test or ANOVA to determine the significant differences between groups for the numerical data. Chi-squared test was used for categorical data. When the data were not normally distributed Kruskal Wallis test for comparison of three groups. Qualitative data were presented as number and percentage. Spearman correlation analysis was done to find the correlation between EDSS and different variables preceded by preliminary analyses to ensure no violation of the assumptions of normality, linearity and homoscedasticity. Value was considered significant if it was less than 0.05 .

\section{Results}

The study was carried on 80 patients with MS [36 males (45\%) and 44 females (55\%)] and 20 healthy control [8 males (40\%) and 12 females (60\%)] (Tables 1, 2). The mean age of patients was $33.2 \pm 8.6$ years (range 20-50) and the mean age of healthy controls was $33.5 \pm 10.5$ years (range 19-50) (Table 2). Most of the patients lie in group 2 "Minimal to mild disability" with percent $40 \%$. Only $35 \%$ of the total number of patients received disease modifying therapy (DMT), while 75\% of them were receiving symptomatic treatment (Table 1 ). There was significant difference between the mean of ADC between patients $(1.37 \pm 0.03)$ and healthy controls group $(0.815 \pm 0.039)$ with $P$ value $<0.001$. Similarly, there was significant difference between MRS parameters in NAWM in MS patients and healthy controls (Table 2, Fig. 1). Patients with "moderate disability" group showed a longer disease duration and more frequent attacks per year than those with "no disability" group (Table 3).

In comparison between three groups of disability regarding cMRI findings we found the number of the plaques on T2 WI and black holes were more at 
Table 1 The natural history of multiple sclerosis: a geographically based study 9: observations on the progressive phase of the disease

\begin{tabular}{|c|c|c|}
\hline & Number & Percent \\
\hline Age & $33.20 \pm 8.6$ & \\
\hline \multicolumn{3}{|l|}{ Sex } \\
\hline Male & 36 & 45.0 \\
\hline Female & 44 & 55.0 \\
\hline \multicolumn{3}{|l|}{ Clinical features } \\
\hline Duration of disease (years) & $4.6 \pm 4.6$ & \\
\hline Number of MS attacks/year & $2.75 \pm 1.049$ & \\
\hline Duration of last attack (months) & $3.3 \pm 3$ & \\
\hline \multicolumn{3}{|l|}{ Disability score (EDSS) } \\
\hline No disability & 28 & 35.0 \\
\hline Minimal & 32 & 40.0 \\
\hline Moderate disability & 20 & 25.0 \\
\hline \multicolumn{3}{|l|}{ Disease modifying therapy (DMT) } \\
\hline No & 52 & 65.0 \\
\hline Yes & 28 & 35.0 \\
\hline Male patients taking DMT & 16 & $44.4 \%$ \\
\hline Female patients taking DMT & 12 & $27.3 \%$ \\
\hline \multicolumn{3}{|l|}{ Symptomatic treatment } \\
\hline No & 20 & 25.0 \\
\hline Yes & 60 & 75.0 \\
\hline \multicolumn{3}{|l|}{ Conventional MRI finding } \\
\hline Number of plaques on $\mathrm{T} 2$ weighted images & $5.80 \pm 3.421$ & \\
\hline Black holes & $3.2 \pm 2.3$ & \\
\hline Enhanced plaques & 24 & 30.0 \\
\hline Non enhanced plaques & 56 & 70.0 \\
\hline \multicolumn{3}{|l|}{ Non-conventional MRI finding } \\
\hline$A D C$ & $1.37 \pm 0.361$ & \\
\hline NAA/Cr NAWM & $1.6 \pm 0.40$ & \\
\hline NAA/Cr plaque & $1.3 \pm 0.46$ & \\
\hline Cho/NAA NAWM & $0.67 \pm 0.08$ & \\
\hline Cho/NAA plaque & $0.72 \pm 0.08$ & \\
\hline Cho/Cr NAWM & $1.01 \pm 0.30$ & \\
\hline Cho/Cr plaque & $1.08 \pm 0.31$ & \\
\hline
\end{tabular}

Cho/Cr choline/creatine; Cho/NAA choline/N-acetyl-aspartate; DMT disease modifying therapy; EDSS expanded disability status scale; NAA/CrN-acetylaspartate/creatine; NAWM normal appearing white matter

"Minimal disability" group with $P$ value 0.001 and 0.037 , respectively. While Most of enhanced plaques were more at the "Moderate disability" group with $p$ value $<0.001$ (Table 3). We found the mean of ADC in the group 1, 2 and 3 of disability was $1.12 \pm 0.19$, $1.50 \pm 0.35,1.51 \pm 0.36$, respectively, with $P$ value $<0$. 001 . Likewise the mean of the $\mathrm{NAA} / \mathrm{Cr}$ ratio at the plaque was $1.34 \pm 0.44,1.59 \pm 0.51,1.11 \pm 0.15$ with $P$
Table 2 Comparison between patients with MS and healthy controls

\begin{tabular}{|c|c|c|c|}
\hline & $\begin{array}{l}\text { Patients with MS } \\
N=80\end{array}$ & $\begin{array}{l}\text { Control } \\
N=20\end{array}$ & $P$ value \\
\hline Age (year) & $33.20 \pm 8.6$ & $33.5 \pm 10.5$ & 0.144 \\
\hline Sex & & & 0.687 \\
\hline Male & $36(45)$ & $8(40)$ & \\
\hline Female & $44(55)$ & $12(60)$ & \\
\hline EDSS & & & $<0.001$ \\
\hline No disability & $28(35.0 \%)$ & $0(0.0 \%)$ & \\
\hline Minimal & $32(40.0 \%)$ & $0(0.0 \%)$ & \\
\hline Moderate disability & $20(25.0 \%)$ & $0(0.0 \%)$ & \\
\hline EDSS Score (mean \pm SD) & $2.4 \pm 1.2$ & $0.0 \pm 0.0$ & \\
\hline \multicolumn{4}{|l|}{$\begin{array}{l}\text { Non-conventional MRI } \\
\text { finding } \\
(\text { mean } \pm \text { SD) }\end{array}$} \\
\hline$A D C$ & $1.37 \pm 0.03$ & $0.815 \pm 0.039$ & $<0.001$ \\
\hline NAA/Cr NAWM & $1.60 \pm 0.39$ & $2.27 \pm 0.24$ & 0.017 \\
\hline NAA/Cr (plaque) & $1.38 \pm 0.46$ & & \\
\hline Cho/NAA_NAWM & $0.67 \pm 0.08$ & $0.60 \pm 0.052$ & 0.020 \\
\hline Cho/NAA (plaque) & $.7270 \pm .08860$ & & \\
\hline Cho/Cr NAWM & $1.01 \pm 0.308$ & $0.88 \pm 0.049$ & 0.001 \\
\hline Cho/Cr (plaque) & $1.0875 \pm .0302$ & & \\
\hline
\end{tabular}

Cho/Cr choline/creatine; Cho/NAA choline/N-acetyl-aspartate; EDSS expanded disability status scale; $N A A / C r N$-acetyl-aspartate/creatine; NAWM normal appearing white matter

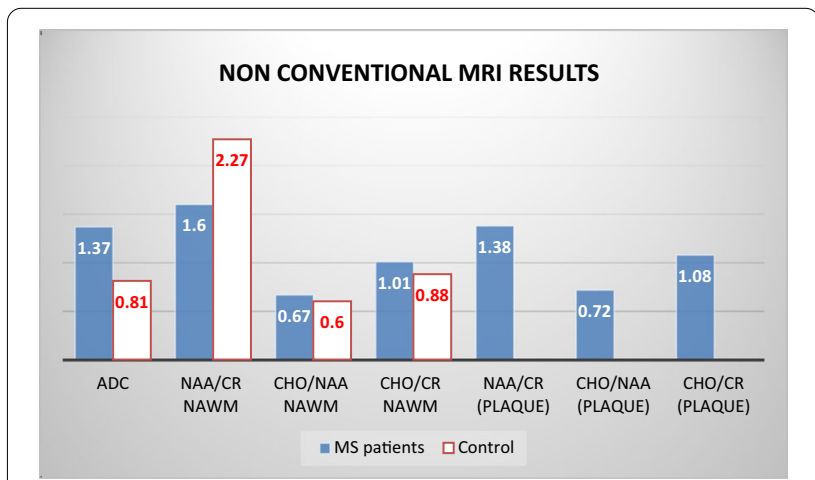

Fig. 1 Difference between patients with and healthy controls as regard non-conventional MRI techniques

value 0.001 (Table 3, Figs. 2, 3, 4). There was an insignificant difference between disability group 1, 2 and 3 in comparing the mean of metabolic changes, namely; NAA/Cr, Cho/NAA, Cho/Cr of NAWM and the Cho/ $\mathrm{NAA}$ and $\mathrm{Cho} / \mathrm{Cr}$ at the plaque (Table 3). There was a significant correlation between ADC and disability $(r=0.42$ and $P$ value $<0.001)$ (Table 4$)$. 
Table 3 Comparison between patients in different disability groups according to EDSS

\begin{tabular}{|c|c|c|c|c|}
\hline & $\begin{array}{l}\text { No disability } \\
N=28\end{array}$ & $\begin{array}{l}\text { Minimal disability } \\
N=32\end{array}$ & $\begin{array}{l}\text { Moderate disability } \\
N=20\end{array}$ & $P$ value \\
\hline Age (year) mean $\pm S D$ & $35.7 \pm 10.1$ & $30.7 \pm 6.6$ & $33.6 \pm 8.6$ & 0.081 \\
\hline Sex & & & & 0.011 \\
\hline Male & $12(42.9 \%)$ & $20(62.5 \%)$ & $4(20.0 \%)$ & \\
\hline Female & $16(57.1 \%)$ & $12(37.5 \%)$ & $16(80.0 \%)$ & \\
\hline Duration (years) & $1.6 \pm 2.2$ & $6.2 \pm 5.1$ & $6.3 \pm 4.5$ & $<0.001$ \\
\hline Number of attacks/years & $2 \pm 0.5$ & $3 \pm 1.2$ & $3.4 \pm 0.5$ & $<0.001$ \\
\hline Disease modifying therapy & & & & 0.000 \\
\hline No & $24(85.7 \%)$ & $12(37.5 \%)$ & $16(80.0 \%)$ & \\
\hline Yes & $4(14.3 \%)$ & $20(62.5 \%)$ & $4(20.0 \%)$ & \\
\hline Symptomatic treatment & & & & 0.000 \\
\hline No & $(57.1 \%)$ & $4(12.5 \%)$ & $0(0.0 \%)$ & \\
\hline Yes & $12(42.9 \%)$ & $28(87.5 \%)$ & $20(100.0 \%)$ & \\
\hline \multicolumn{5}{|l|}{ Conventional MRI (cMRI) } \\
\hline $\begin{array}{l}\text { Number of plaques on } \mathrm{T} 2 \text { weighted } \\
\text { images }\end{array}$ & $4 \pm 1.3$ & $7 \pm 3.9$ & $6.4 \pm 3.5$ & 0.001 \\
\hline Black holes & $2.8 \pm 1.2$ & $4 \pm 2.1$ & $2.4 \pm 3.4$ & 0.037 \\
\hline Enhanced plaques & $12(42.9 \%)$ & $0(0.0 \%)$ & $12(60.0 \%)$ & $<0.001$ \\
\hline \multicolumn{5}{|l|}{ Non-conventional MRI } \\
\hline$A D C$ & $1.12 \pm 0.19$ & $1.50 \pm 0.35$ & $1.51 \pm 0.36$ & $<0.001$ \\
\hline NAA/Cr NAWM & $1.67 \pm 0.03$ & $1.6 \pm 0.45$ & $1.49 \pm .033$ & 0.297 \\
\hline NAA/Cr plaque & $1.34 \pm 0.44$ & $1.59 \pm 0.51$ & $1.11 \pm 0.15$ & 0.001 \\
\hline Cho/NAA_NAWM & $0.65 \pm 0.07$ & $0.69 \pm .082$ & $0.67 \pm 0.08$ & 0.094 \\
\hline Cho/NAA plaque & $0.72 \pm 0.08$ & $0.71 \pm 0.10$ & $0.74 \pm 0.06$ & 0.580 \\
\hline Cho/Cr NAWM & $1.05 \pm 0.48$ & $0.98 \pm 0.16$ & $0.98 \pm 0.13$ & 0.636 \\
\hline Cho/Cr plaque & $1.15 \pm 0.42$ & $1.03 \pm 0.21$ & $1.07 \pm 0.21$ & 0.296 \\
\hline
\end{tabular}

Cho/Cr choline/creatine; Cho/NAA choline/N-acetyl-aspartate; NAA/CrN-acetyl-aspartate/creatine; EDSS expanded disability status scale; NAWM normal appearing white matter

(See figure on next page.)

Fig. 2 A 32-year-old female diagnosed as RRMS showing multiple plaques; single voxel MR spectroscopy with ROI was placed at corona radiata plaque (a); showing decreased NAA curve and mildly elevated choline curve, which is correlated by Low NAA/Cr ratio 1.38 and elevated choline/ Cr ratio 1.09. b ROI was placed at NAWM, more lateral to the plaque showing decreased NAA curve and mildly elevated choline curve, which is correlated by Low NAA/Cr ratio 1.55 and elevated choline/Cr ratio 1.01

\section{Discussion}

MS is a complex immune-mediated disorder affecting the brain and spinal cord and it is associated with inflammation, demyelination, gliosis and axonal degeneration [28, 29]. cMRI techniques play a crucial role in the diagnosis of MS $[4,30]$ but, they have a limited role in evaluating the different events involved in MS pathogenesis particularly in NAWM [22, 29, 31, 32]. In contrary, the advanced MRI techniques, may detect different metabolic changes in NAWM, and provide more assertive diagnostic and prognostic criteria, and accurately compare response to different lines of treatment [29].
Most of the previous studies showed that men are more likely to have poorer outcomes [33-36]. In contrast to our study, we found a significant association between female gender and disability and this difference can be explained by the facts that $44.4 \%$ of male patients received DMT, while only about one quarter $(27.3 \%)$ of female patients received that treatment in our group of patients, and so most of the females were exposed to more relapses and subsequent accumulation of disabilities. In addition, RRMS patients only were enrolled in this study with exclusion of secondary and primary progressive MS, which is relatively common in males as reported by Ford et al. [37]. 

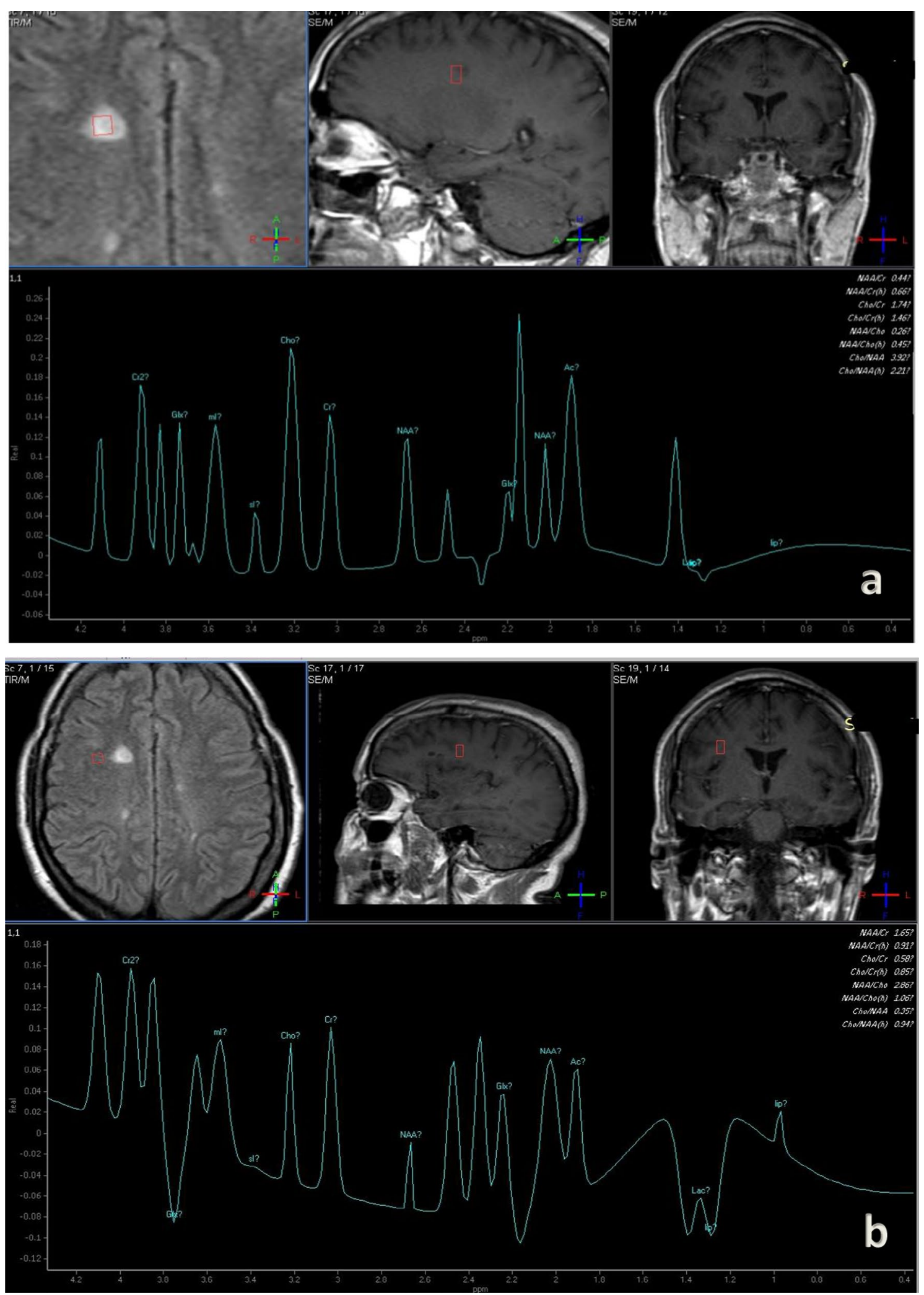

Fig. 2 (See legend on previous page.) 

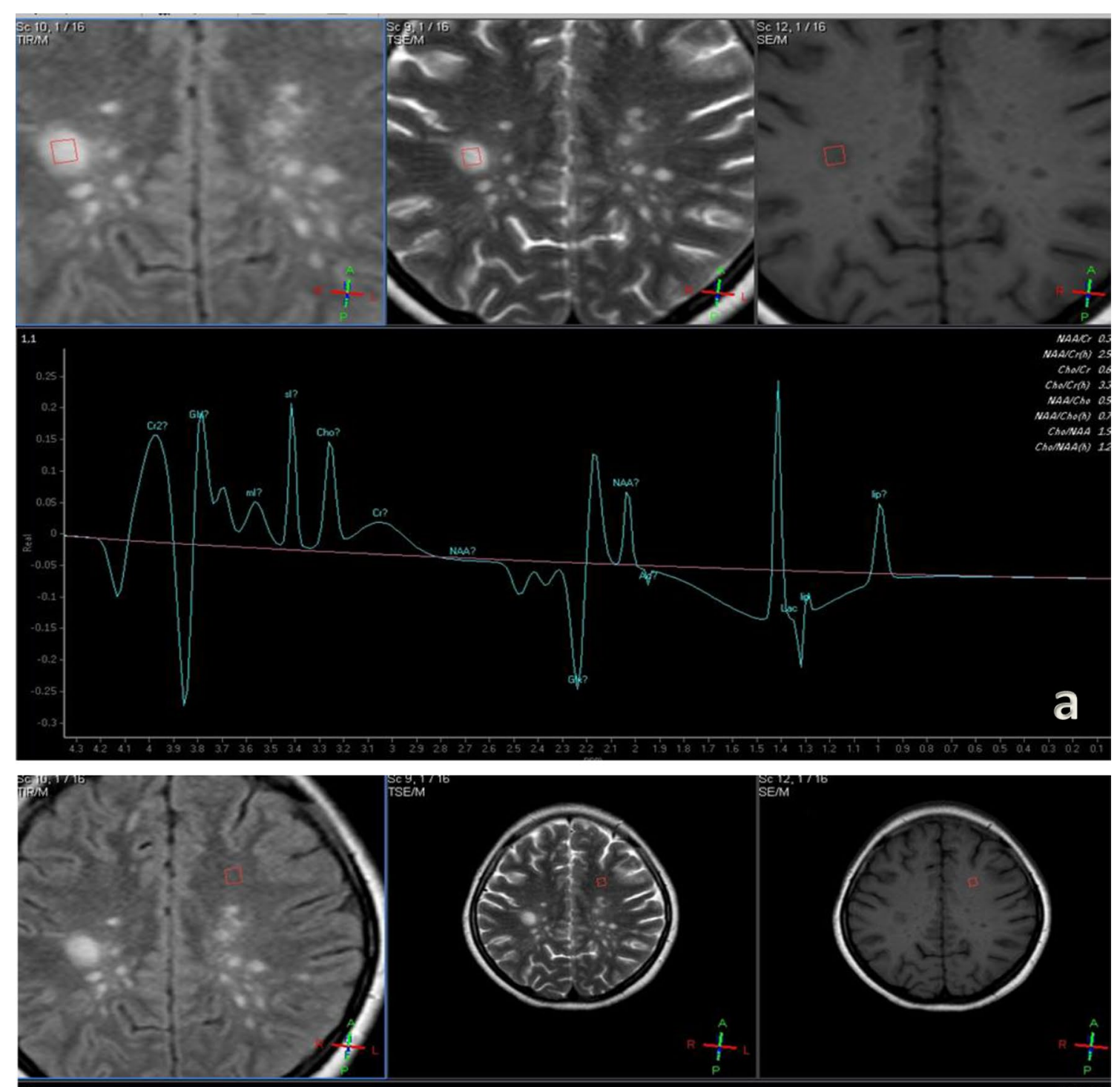

TSEM

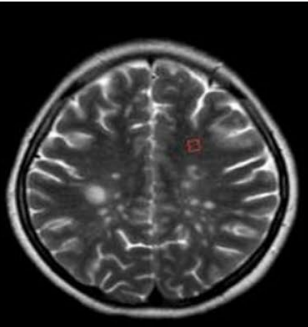

SEM

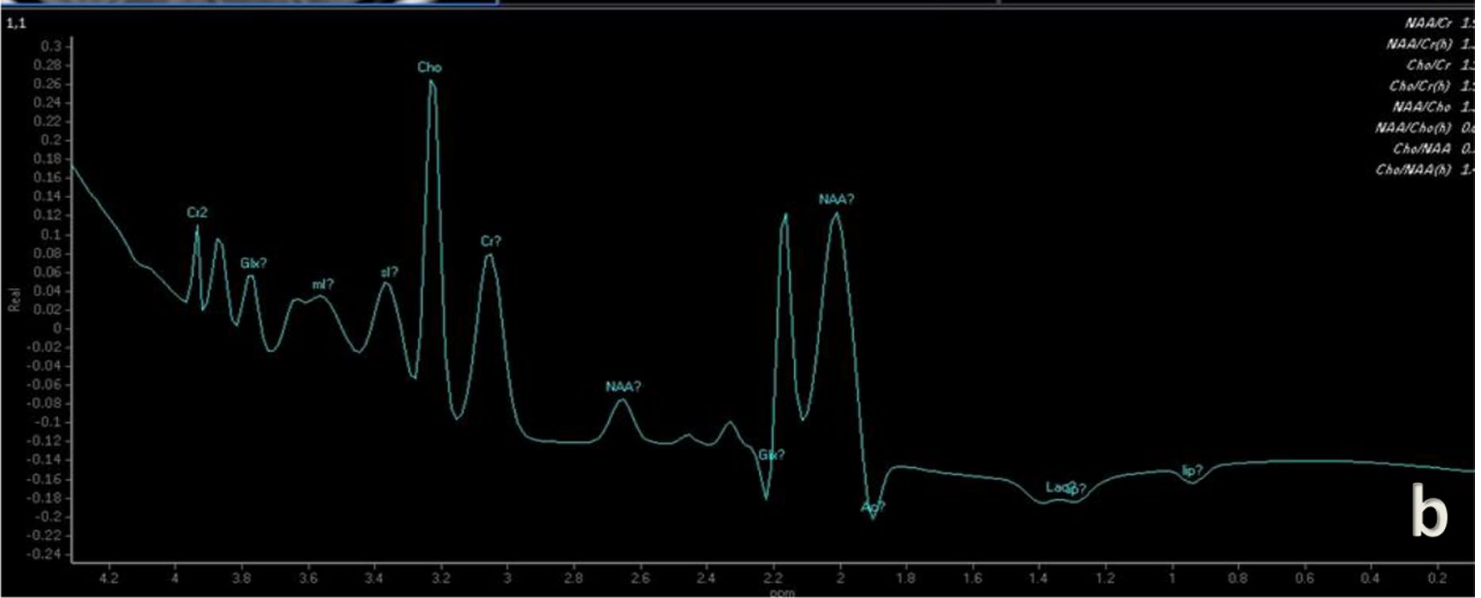

Fig. 3 A 37-year-old female diagnosed at RRMS showing multiple plaques; single voxel MR spectroscopy with ROI was placed at corona radiata plaque a; showing decreased NAA curve and mildly elevated choline curve, which is correlated by Low NAA/Cr ratio 1.44 and elevated choline/Cr ratio 1.06. b ROI placed at NAWM, more lateral to the plaque showing decreased NAA curve and mildly elevated choline curve, which is correlated by Low NAA/Cr ratio 1.45 and elevated choline/Cr ratio 1.21 


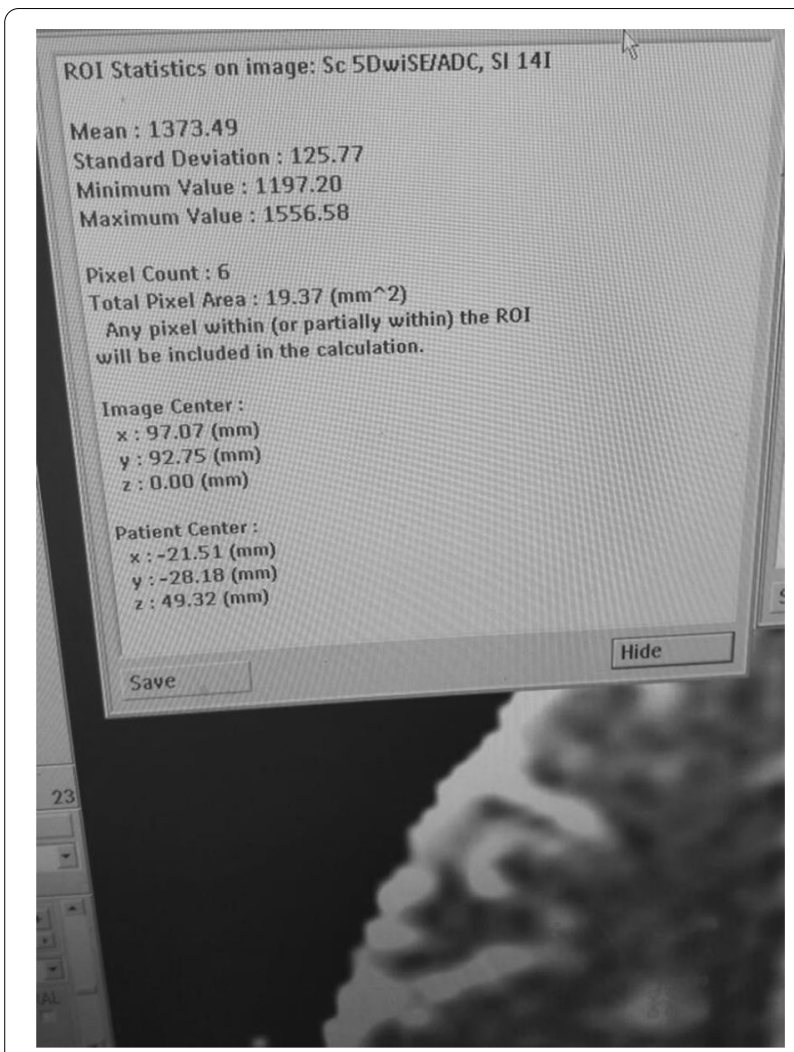

Fig. 4 A 24 year patient diagnosed as RRMS; ROI was placed on an MS plaque at an ADC map for recording the ADC value of $1.373 \times 10^{-3} \mathrm{~mm}^{2} / \mathrm{s}$

Table 4 Correlation between EDSS values and MRI variables in patients with MS

\begin{tabular}{lcc}
\hline Metabolic changes & \multicolumn{2}{l}{ EDSS } \\
\cline { 2 - 3 } & Correlation coefficient & $\boldsymbol{P}$ value \\
\hline ADC & 0.429 & 0.000 \\
NAA/Cr NAWM & -0.171 & 0.128 \\
NAA/Cr lesion & -0.151 & 0.182 \\
Cho/NAA NAWM & 0.106 & 0.350 \\
Cho/NAA lesion & 0.070 & 0.540 \\
Cho/Cr NAWM & -0.093 & 0.411 \\
Cho/Cr lesion & -0.114 & 0.315 \\
\hline
\end{tabular}

Cho/Cr choline/creatine; Cho/NAA choline/N-acetyl-aspartate; EDSS expanded disability status scale; $N A A / C r N$-acetyl-aspartate/creatine; NAWM normal appearing white matter

In this work, we found that there was a significant association between the duration of the disease and moderate disability which is in agreement with Rzepiński et al. who documented that the time from MS onset to a score 6 points on the EDSS scale was $13.9 \pm 6.8$ years for the RRMS and $8.0 \pm 5.1$ for the
PPMS patients $(P<0.001)$ [38]. Similarly in an Egyptian study carried out on 23 patients with clinically definite MS patients there was a significant correlation between disability and duration of the disease $(r=0.416$ and $P$ value $=0.04$ ) [39].

Similar to the previous studies [40-44], we found a significant correlation between number of attacks per year and moderated disability. We also found that moderate disability was significantly associated with enhanced plaques which is an indicator of active lesions and clinical relapses. In addition, the number of plaques on T2 WI is significantly related to minimal disability, which is in line with previous studies that reported a week correlation between the number of lesions on brain MRI and disability, as most of the MRI lesions seen in patients with MS appear to be asymptomatic (clinic-radiological paradox) $[41,45,46]$. The clinic-radiological paradox may be explained by the anatomical locations of the MS lesions. Lesions in the corona radiata or cortex are more likely to produce symptoms than lesions in the periventricular white matter. In addition, lesions in the spinal cord or brainstem are more likely to produce symptoms than lesions in the brain, and so forth [45]. In addition, the occurrence of apparently asymptomatic lesions is quite common in patients with MS, even within the spinal cord $[47,48]$. Thus, only about $5-20 \%$ of new brain MRI lesions are associated with clinical symptoms or signs $[45,49,50]$. Furthermore, the selection bias may play a role as the percent of patient with no or minimal disability represents $35 \%$ and $40 \%$, respectively.

Similar to the previous studies [11,51], we found that the mean ADC in patients with MS is significantly higher than that of the control group $1.37 \pm 0.03$ and $0.815 \pm 0.039$, respectively $(P$ value $<0.001)$. In our study, we found a significant association between ADC measured at the MS plaques and disability score which in line with the previous studies [11, 52]. It has been shown that higher ADC values were identified in acute lesions than in chronic lesions because of demyelination or vasogenic extracellular edema [53]. Mohamed et al. reported that the ADC values measurement can predict histological changes in MS lesions and then disease activity [11]. In contrast to our study, Cercignani et al. [54] failed to find a significant correlation between ADC and disability which can be explained by the fact that they enrolled a relatively small number of MS patients (35 patients with relapsing-remitting MS) in both early and late stages of the disease. DWI shows the movement of water molecules in tissues, and the ADC maps show the quantitative measurement of myelin breakdown [55]. The mean ADC values of MS lesions may show alterations depending on the type of edema during active and chronic disease states [56]. 
The MS lesions may have higher mean ADC values than NAWM $[55,56]$. The measurement of ADC values may allow the detection of NAWM injuries [55].

There was a significant correlation between reduced mean of NAA/Cr ratio for plaques and moderate disability which is consistent with previous studies that confirm a significant relationship between disability and reduced levels of NAA and NAA/Cr ratio $[8,18,57,58]$. NAA is one of the major metabolites of CNS and is considered a reliable marker of axonal integrity in the adult brain [59]. The levels of NAA in various parts of the brain are directly correlated with neuronal health or integrity, while decreased levels of NAA detected by MRS indicate neuronal/axonal loss [60]. Decreased NAA/creatinine ratio (NAA/Cr) has been shown as an indicator of irreversible axonal dysfunction and reduced brain volume [61]. De Stefano et al. [61] demonstrated a significant correlation between changes in NAA/Cr ratio in NAWM and disability score (measured by EDSS), concluding that axonal damage in NAWM is important in the understanding of chronic disability in MS.

The mean NAA/Cr ratio of NAWAM of our study was significantly lower than that of healthy controls group $(1.60 \pm 0.39$ and $2.27 \pm 0.24$, respectively, with $P$ value $=0.017)$. This finding was confirmed by Matthews et al. [62], who found low NAA in NAWM of patients with MS, suggesting a diffuse and early axonal involvement beyond macroscopic lesions. However, we did not find significant correlation between the decreased NAA/ $\mathrm{Cr}$ for NAWM and disability $(P$ value $=0.2)$ as we collected MS patient at early stage with EDSS is 4.5 or less. In contrast to our study, a previous study conducted on 31 patients with clinically definite MS and found a significant correlation between the NAA/Cr ratio in NAWM and disability as measured by EDSS score $(r=-0.38$; $P<0.03$ ) [63] as they recruited a relatively smaller number patients (31) and extended their selection to enrolled patients with EDSS scores up to 5.5.

In comparing MS patient and control subjects, we found a significant increase in Cho/NAA ratio for NAWM (as the levels of NAA was decreased) and Cho/ $\mathrm{Cr}$ ratio for NAWM. Previous work documented a "clinical silent" focal or diffuse "background inflammation" in very early stages of RRMS not detectable in cMRI may cause diffuse axonal damage and this subtle axonal degeneration may be visualized by MRS as reduction of NAA levels $[64,65]$. An increase of choline/creatine $(\mathrm{Cho} / \mathrm{Cr})$ ratio has been considered as a marker of increased membrane cell turnover in active MS plaques [61, 66-68]. Cho and $\mathrm{Cr}$ as well as NAA reflect a range of pathological processes, prevalent in NAWM of MS patients, occurring even during the clinically calm phase of the disease [69].
Acute axonal damage is secondary to axon transection in the setting of inflammatory demyelination [9], while progressive axonal degeneration may be related to lack of trophic support from oligodendroglia and myelin [70]. Some authors have suggested that a cell-mediated autoimmune response occurs against extraneous or even the body's own components, with the consequent damage of oligodendrocytes and progressive axonal degeneration $[71,72]$. One mechanism of this neurodegeneration might be associated with the production of reactive oxygen species from activated microglia and macrophages with a subsequent inadequate energy supply to the CNS $[7,73]$.

We did not find any significant association between disability in patients with MS and Cho/NAA, Cho/Cr of NAWM and Cho/NAA, and Cho/Cr ratio of plaque. Similar to previous study which failed to demonstrate a significant correlation between EDSS and absolute values of creatine, choline, NAA/Cr and NAA/Cho in either NAWM or MS plaques [39]. This study has some restrictions that should be brought into account in evaluating the results. One is the unavailability of functional MRI techniques which were applied only in selected research centers. We did not compare metabolic changes in gadolinium enhancing and non-enhancing lesions of MS or with other quantitative MRI modalities (for example, Magnetization transfer imaging, or T1 mapping). In spite of these restrictions, it was one of the few studies that has been used MRS to characterize the metabolic changes in MS patients in both NAWM and plaque and investigate the relationship between these metabolic changes and early disability in patients with MS. The detection of the early disability of noninvasive radiological biomarkers may facilitate early diagnosis and the expansion of DMT and /or application of neuroprotective treatments for MS.

\section{Conclusion}

The non-conventional MRI techniques including ADC and metabolic measurements (NAA, $\mathrm{Cr}$ and $\mathrm{Cho}$ ) are clinically useful tools for detection of early disability in patients with MS.

\footnotetext{
Abbreviations

ADC: Apparent diffusion coefficient; ANOVA: Analysis of variance; CE-MRI: Contrast enhancement MRI; CHESS: Chemical shift selective imaging sequence; Cho: Choline; Cho/Cr: Choline creatine; Cho/NAA: Choline/N-acetyl-aspartate; CMRI: Conventional magnetic resonance imaging; CNS: Central nervous system; Cr: Creatine; EDSS: Expanded Disability Status Scale; EPI: Echo Planar Imaging; FOV: Field of view; Gd-DTPA: Gadolinium (diethelene triamine penta acidic acid); MS: Multiple sclerosis; NAA: N-acetyl-aspartate; NAA/Cr: N-acetylaspartate/creatine; NAWM: Normal appearing white matter; RIS: Radiologically isolated syndrome; RRMS: Relapsing-remitting multiple sclerosis; SPSS: Statistical Package for the Social Sciences for Windows; T2Wl: T2 weighted images; VOI: Volume Voxel of interest.
} 


\section{Acknowledgements \\ Not applicable.}

\section{Authors' contributions}

$A A B$, is responsible for the design and implementation of the research, to the analysis of the results and to the writing and reviewing of the manuscript. $M N$ and $\mathrm{HA}$, are participating in the design and implementation of the research, in the analysis of the results and to reviewing of the manuscript. All authors read and approved the final manuscript.

\section{Funding}

None.

\section{Availability of data and materials}

The data set of this work is available.

\section{Declarations}

\section{Ethics approval and consent to participate}

The study was approved by the local ethical committee in Faculty of Medicine, Sohag University in June-2018. (The committee's reference number is not available). Informed written consent was obtained from all patients for participation and publication of this study.

\section{Consent for publication}

Not applicable.

\section{Competing interests}

There were no financial or non-financial conflict of interest.

\section{Author details}

${ }^{1}$ Department of Neurology and Psychological Medicine, Sohag University, Sohâg, Egypt. ²Department of Diagnostic Radiology, Sohag University, Sohâg, Egypt. ${ }^{3}$ Sohag University Hospital, El Kawaser, P.O. Box 82524, Sohâg 82524, Egypt.

Received: 21 February 2021 Accepted: 28 January 2022

Published online: 10 February 2022

\section{References}

1. da Cruz LCH, Batista RR, Domingues RC, Barkhof F. Diffusion magnetic resonance imaging in multiple sclerosis. Neuroimaging Clin 2011;21(1):71-88

2. Kamińska J, Koper OM, Piechal K, Kemona H. Multiple sclerosis-etiology and diagnostic potential. Postepy Hig Med Dosw (Online). 2017;71:551-63.

3. Dutta R, McDonough J, Yin X, Peterson J, Chang A, Torres T, et al. Mitochondrial dysfunction as a cause of axonal degeneration in multiple sclerosis patients. Ann Neurol. 2006:59(3):478-89.

4. Messina S, Patti F. Gray matters in multiple sclerosis: cognitive impairment and structural MRI. Multiple Scler Int. 2014. https://doi.org/10.1155/2014/ 609694

5. Trapp BD, Peterson J, Ransohoff RM, Rudick R, Mörk S, Bö L. Axonal transection in the lesions of multiple sclerosis. N Engl J Med. 1998:338(5):278-85.

6. Van Waesberghe J-HT, Kamphorst W, De Groot CJ, Van Walderveen MA, Castelijns JA, Ravid R, et al. Axonal loss in multiple sclerosis lesions: magnetic resonance imaging insights into substrates of disability. Ann Neurol. 1999;46(5):747-54.

7. Haider L, Simeonidou C, Steinberger G, Hametner S, Grigoriadis N, Deretz $\mathrm{G}$, et al. Multiple sclerosis deep grey matter: the relation between demyelination, neurodegeneration, inflammation and iron. J Neurol Neurosurg Psychiatry. 2014;85(12):1386-95.

8. Simone I, Tortorella C, Federico F, Liguori M, Lucivero V, Giannini P, et al. Axonal damage in multiple sclerosis plaques: a combined magnetic resonance imaging and $1 \mathrm{H}$-magnetic resonance spectroscopy study. J Neurol Sci. 2001;182(2):143-50.
9. Kuhlmann T, Lingfeld G, Bitsch A, Schuchardt J, Brück W. Acute axonal damage in multiple sclerosis is most extensive in early disease stages and decreases over time. Brain. 2002;125(10):2202-12.

10. Andreadou E, Bright P. Neuroimaging in multiple sclerosis. Neuroimaging-Clinical Applications. 2012; p. 317-54.

11. Mohamed FF, Almassry HN, Sharaf MH. ADC value as a predictor for myelin loss/preservation in MS plaques with different enhancement pattern in correlation with disease activity. Egypt J Radiol Nucl Med. 2017:48(4):991-7.

12. Sbardella E, Tona F, Petsas N, Pantano P. DTI measurements in multiple sclerosis: evaluation of brain damage and clinical implications. Multiple Scler Int. 2013. https://doi.org/10.1155/2013/671730.

13. Qian J, Herrera JJ, Narayana PA. Neuronal and axonal degeneration in experimental spinal cord injury: in vivo proton magnetic resonance spectroscopy and histology. J Neurotrauma. 2010;27(3):599-610.

14. Ciccarelli O, Barkhof F, Bodini B, De Stefano N, Golay X, Nicolay K, et al. Pathogenesis of multiple sclerosis: insights from molecular and metabolic imaging. Lancet Neurol. 2014;13(8):807-22.

15. Bertholdo D, Watcharakorn A, Castillo M. Brain proton magnetic resonance spectroscopy: introduction and overview. Neuroimaging Clin. 2013;23(3):359-80

16. Stromillo ML, Giorgio A, Rossi F, Battaglini M, Hakiki B, Malentacchi G, et al. Brain metabolic changes suggestive of axonal damage in radiologically isolated syndrome. Neurology. 2013;80(23):2090-4.

17. Rovira À, Alonso J. $1 \mathrm{H}$ magnetic resonance spectroscopy in multiple sclerosis and related disorders. Neuroimaging Clin. 2013;23(3):459-74.

18. Filippi M, Rocca M, Benedict R, DeLuca J, Geurts J, Rombouts S, et al. The contribution of MRI in assessing cognitive impairment in multiple sclerosis. Neurology. 2010;75(23):2121-8.

19. Miller D, Grossman R, Reingold S, McFarland $H$. The role of magnetic resonance techniques in understanding and managing multiple sclerosis. Brain. 1998;121(1):3-24

20. Filippi M, Tortorella C, Rovaris M, Bozzali M, Possa F, Sormani M, et al. Changes in the normal appearing brain tissue and cognitive impairment in multiple sclerosis. J Neurol Neurosurg Psychiatry. 2000;68(2):157-61.

21. Anik Y, Demirci A, Efendi H, Bulut S, Celebi I, Komsuoglu S. Evaluation of normal appearing white matter in multiple sclerosis. Clin Neuroradiol. 2011:21(4):207-15.

22. Hemond CC, Bakshi R. Magnetic resonance imaging in multiple sclerosis. Cold Spring Harb Perspect Med. 2018:8(5):a028969.

23. Bakshi R, Thompson AJ, Rocca MA, Pelletier D, Dousset V, Barkhof F, et al. MRI in multiple sclerosis: current status and future prospects. Lancet Neurol. 2008;7(7):615-25

24. Thompson AJ, Banwell BL, Barkhof F, Carroll WM, Coetzee T, Comi G, et al. Diagnosis of multiple sclerosis: 2017 revisions of the McDonald criteria. Lancet Neurol. 2018;17(2):162-73.

25. Ömerhoca S, Akkaş SY, İçen NK. Multiple sclerosis: diagnosis and differential diagnosis. Noro psikiyatri arsivi. 2018;55(Suppl 1):S1-9.

26. Kurtzke JF. Rating neurologic impairment in multiple sclerosis: an expanded disability status scale (EDSS). Neurology. 1983;33(11):1444.

27. Filippi M, Preziosa P, Banwell BL, Barkhof F, Ciccarelli O, De Stefano N, et al. Assessment of lesions on magnetic resonance imaging in multiple sclerosis: practical guidelines. Brain. 2019:142(7):1858-75.

28. Miller AE, Rhoades RW. Treatment of relapsing-remitting multiple sclerosis: current approaches and unmet needs. Curr Opin Neurol. 2012;25(Suppl):S4-10

29. Londoño AC, Mora CA. Nonconventional MRI biomarkers for in vivo monitoring of pathogenesis in multiple sclerosis. Neurol Neuroimmunol Neuroinflamm. 2014;1(4):e45

30. Sajja BR, Wolinsky JS, Narayana PA. Proton magnetic resonance spectroscopy in multiple sclerosis. Neuroimaging Clin N Am. 2009;19(1):45-58.

31. McFarland HF. Examination of the role of magnetic resonance imaging in multiple sclerosis: a problem-orientated approach. Ann Indian Acad Neurol. 2009:12(4):254.

32. Napoli SQ, Bakshi R. Magnetic resonance imaging in multiple sclerosis. Rev Neurol Dis. 2005:2(3):109-16.

33. Tomassini $\mathrm{V}$, Pozzilli C. Sex hormones, brain damage and clinical course of multiple sclerosis. J Neurol Sci. 2009;286(1-2):35-9.

34. Tomassini $\bigvee$, Pozzilli C. Sex hormones: a role in the control of multiple sclerosis? Expert Opin Pharmacother. 2006;7(7):857-68. 
35. Runmarker B, Andersen O. Prognostic factors in a multiple sclerosis incidence cohort with twenty-five years of follow-up. Brain 1993:116(1):117-34.

36. Kantarci O, Wingerchuk D. Epidemiology and natural history of multiple sclerosis: new insights. Curr Opin Neurol. 2006;19(3):248-54.

37. Ford DV, Jones KH, Middleton RM, Lockhart-Jones H, Maramba ID, Noble GJ, et al. The feasibility of collecting information from people with multiple sclerosis for the UK MS Register via a web portal: characterising a cohort of people with MS. BMC Med Inform Decis Mak. 2012;12(1):1-8.

38. Rzepiński Ł, Zawadka-Kunikowska M, Maciejek Z, Newton JL, Zalewski P. Early clinical features, time to secondary progression, and disability milestones in polish multiple sclerosis patients. Medicina (Kaunas). 2019:55(6):232.

39. Mohamed Ahmed EES, Zaiton MA, Hassan HAE, ElSayed WM, Shawki KM. Magnetic resonance spectroscopy of normal appearing white matter in early relapsing-remitting multiple sclerosis. Zagazig Univ Med J. 2018;24(3):200-7.

40. Confavreux C, Vukusic S, Adeleine P. Early clinical predictors and progression of irreversible disability in multiple sclerosis: an amnesic process. Brain. 2003;126(4):770-82

41. Goodin DS, Reder AT, Bermel RA, Cutter GR, Fox RJ, John GR, et al. Relapses in multiple sclerosis: relationship to disability. Multiple Scler Relat Disord. 2016;6:10-20.

42. Confavreux C, Vukusic S. Natural history of multiple sclerosis: a unifying concept. Brain. 2006;129(3):606-16.

43. Kremenchutzky M, Rice G, Baskerville J, Wingerchuk DM, Ebers GC. The natural history of multiple sclerosis: a geographically based study 9: observations on the progressive phase of the disease. Brain. 2006;129:584-94.

44. Scalfari A, Neuhaus A, Degenhardt A, Rice GP, Muraro PA, Daumer M, et al. The natural history of multiple sclerosis, a geographically based study 10 : relapses and long-term disability. Brain. 2010;133(7):1914-29.

45. Goodin DS. Magnetic resonance imaging as a surrogate outcome measure of disability in multiple sclerosis: have we been overly harsh in our assessment? Ann Neurol. 2006;59(4):597-605.

46. Barkhof F. The clinico-radiological paradox in multiple sclerosis revisited. Curr Opin Neurol. 2002;15(3):239-45.

47. Silver N, Good C, Sormani M, MacManus D, Thompson A, Filippi M, et al. A modified protocol to improve the detection of enhancing brain and spinal cord leasions in multiple sclerosis. J Neurol. 2001;248(3):215-24.

48. à Nijeholt GL, Uitdehaag B, Bergers E, Castelijns J, Polman C, Barkhof F. Spinal cord magnetic resonance imaging in suspected multiple sclerosis. Eur Radiol. 2000;10(2):368-76.

49. Frank JA, Stone LA, Smith ME, Albert PS, Maloni H, McFarland HF. Serial contrast-enhanced magnetic resonance imaging in patients with early relapsing-remitting multiple sclerosis: implications for treatment trials. Ann Neurol. 1994:36(S1):S86-90.

50. Miller DH, Khan OA, Sheremata WA, Blumhardt LD, Rice GP, Libonati MA, et al. A controlled trial of natalizumab for relapsing multiple sclerosis. $\mathrm{N}$ Engl J Med. 2003;348(1):15-23.

51. Tievsky AL, Ptak T, Farkas J. Investigation of apparent diffusion coefficient and diffusion tensor anisotropy in acute and chronic multiple sclerosis lesions. Am J Neuroradiol. 1999:20(8):1491-9.

52. Gratsias G, Kapsalaki E, Kogia S, Dardiotis E, Tsimourtou V, Lavdas E, et al. A quantitative evaluation of damage in normal appearing white matter in patients with multiple sclerosis using diffusion tensor MR imaging at $3 \mathrm{~T}$. Acta Neurol Belg. 2015;115(2):111-6.

53. Inglese $M$, Bester M. Diffusion imaging in multiple sclerosis: research and clinical implications. NMR Biomed. 2010;23(7):865-72.

54. Cercignani M, lannucci G, Rocca M, Comi G, Horsfield M, Filippi M. Pathologic damage in MS assessed by diffusion-weighted and magnetization transfer MRI. Neurology. 2000;54(5):1139-44.

55. Almolla RM, Hassan HA, Raya YM, Hussein RA. Correlation of apparent diffusion coefficient to cognitive impairment in relapsing remittent multiple sclerosis (plaque, peri-plaque and normal appearing white matter). Egypt J Radiol Nucl Med. 2016;47(3):1009-18.

56. Yurtsever I, Hakyemez B, Taskapilioglu O, Erdogan C, Turan OF, Parlak M. The contribution of diffusion-weighted MR imaging in multiple sclerosis during acute attack. Eur J Radiol. 2008;65(3):421-6.

57. Matthews P, De Stefano N, Narayanan S, Francis G, Wolinsky J, Antel J, et al. Putting magnetic resonance spectroscopy studies in context: axonal damage and disability in multiple sclerosis. Semin Neurol. 1998. https:// doi.org/10.1055/s-2008-1040884.

58. Birken $\mathrm{DL}$, Oldendorf WH. N-acetyl-L-aspartic acid: a literature review of a compound prominent in $1 \mathrm{H}-\mathrm{NMR}$ spectroscopic studies of brain. Neurosci Biobehav Rev. 1989;13(1):23-31.

59. De Stefano N, Narayanan S, Francis GS, Arnaoutelis R, Tartaglia MC, Antel $\mathrm{JP}$, et al. Evidence of axonal damage in the early stages of multiple sclerosis and its relevance to disability. Arch Neurol. 2001;58(1):65-70.

60. Göçmen R. The relevance of neuroimaging findings to physical disability in multiple sclerosis. Arch Neuropsychiatry. 2018;55(Suppl 1):S31.

61. De Stefano N, Matthews PM, Fu L, Narayanan S, Stanley J, Francis GS, et al. Axonal damage correlates with disability in patients with relapsingremitting multiple sclerosis. Results of a longitudinal magnetic resonance spectroscopy study. Brain. 1998;121(8):1469-77.

62. Fu L, Matthews P, De Stefano N, Worsley K, Narayanan S, Francis G, et al. Imaging axonal damage of normal-appearing white matter in multiple sclerosis. Brain. 1998;121(1):103-13.

63. Ruiz-Peña JL, Piñero P, Sellers G, Argente J, Casado A, Foronda J, et al. Magnetic resonance spectroscopy of normal appearing white matter in early relapsing-remitting multiple sclerosis: correlations between disability and spectroscopy. BMC Neurol. 2004;4:8.

64. Chard DT, Griffin CM, MCLean MA, Kapeller P, Kapoor R, Thompson AJ, et al. Brain metabolite changes in cortical grey and normal-appearing white matter in clinically early relapsing-remitting multiple sclerosis. Brain. 2002;125(Pt 10):2342-52.

65. Wattjes M, Harzheim M, Lutterbey G, Klotz L, Schild H, Träber F. Axonal damage but no increased glial cell activity in the normal-appearing white matter of patients with clinically isolated syndromes suggestive of multiple sclerosis using high-field magnetic resonance spectroscopy. Am J Neuroradiol. 2007;28(8):1517-22.

66. Simone IL, Federico F, Trojano M, Tortorella C, Liguori M, Giannini P, et al. High resolution proton MR spectroscopy of cerebrospinal fluid in MS patients. Comparison with biochemical changes in demyelinating plaques. J Neurol Sci. 1996;144(1-2):182-90.

67. Miller D, Austin S, Connelly A, Youl B, Gadian D. Proton magnetic resonance spectroscopy of an acute and chronic lesion in multiple sclerosis. Lancet (British edition). 1991;337(8732):58-9.

68. Bitsch A, Bruhn H, Vougioukas V, Stringaris A, Lassmann H, Frahm J, et al. Inflammatory CNS demyelination: histopathologic correlation with in vivo quantitative proton MR spectroscopy. Am J Neuroradiol. 1999;20(9):1619-27.

69. Inglese M, Li BS, Rusinek H, Babb JS, Grossman RI, Gonen O. Diffusely elevated cerebral choline and creatine in relapsing-remitting multiple sclerosis. Magn Reson Med. 2003;50(1):190-5.

70. Kornek B, Storch MK, Weissert R, Wallstroem E, Stefferl A, Olsson T, et al. Multiple sclerosis and chronic autoimmune encephalomyelitis: a comparative quantitative study of axonal injury in active, inactive, and remyelinated lesions. Am J Pathol. 2000;157(1):267-76.

71. van Rensburg SJ, Kotze MJ, Van Toorn R. The conundrum of iron in multiple sclerosis-time for an individualised approach. Metab Brain Dis. 2012;27(3):239-53.

72. Hohlfeld R. 'Gimme five': future challenges in multiple sclerosis. ECTRIMS Lecture 2009. Multiple Scler J. 2010;16(1):3-14.

73. Steen C, Wilczak N, Hoogduin JM, Koch M, De Keyser J. Reduced creatine kinase $B$ activity in multiple sclerosis normal appearing white matter. PLoS ONE. 2010;5(5):e10811.

\section{Publisher's Note}

Springer Nature remains neutral with regard to jurisdictional claims in published maps and institutional affiliations. 